\section{Ciência e conservação na Floresta Nacional de Caxiuanã, Pará}

Por Maria das Graças Ferraz Bezerra

Doutora em Ciências Sociais pela Universidade Federal do Pará. Analista em Ciência e Tecnologia do Museu Paraense Emilio Goeldi (gferraz@museu-goeldi.br)

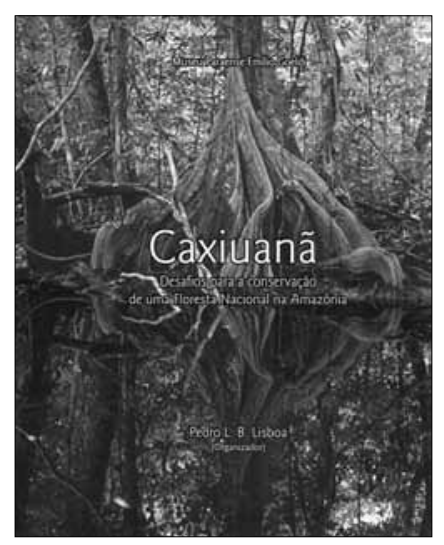

LISBOA, Pedro Luiz Braga

(Org.). Caxiuanã: desafios para a conservação de uma floresta nacional na Amazônia. Belém: Museu Paraense Emílio Goeldi, 2009. 672 p.: il. ISBN 978-85-61377-07-6.

Organizar os trabalhos científicos realizados na Floresta Nacional (FLONA) de Caxiuanã, sob um título específico, foi um dos grandes desafios assumidos pelo Museu Paraense Emílio Goeldi desde a implantação da Estação Científica Ferreira Penna (ECFP). No momento em que é lançado o terceiro volume sobre Caxiuanã, constata-se que este objetivo vem sendo alcançado e que a comunidade científica e a sociedade em geral ganham um presente de inegável valor. $\bigcirc$ novo livro, "Caxiuanã: desafios para a conservação de uma floresta nacional na Amazônia", organizado pelo botânico Pedro Luiz Braga Lisboa, pesquisador do Museu Goeldi também responsável pela organização dos dois anteriores, é composto por seis partes, sendo que cada uma trata de uma área específica.

A exemplo das publicações anteriores, o tema inicial abordado versa sobre a própria Estação Científica Ferreira Penna. $O$ texto condensa o desempenho das atividades na ECFP nos últimos 15 anos, destacando o salto exponencial na produção científica no ano de 2002, refletindo a organização e o lançamento do primeiro e do segundo volume sobre Caxiuanã. Demonstra, ainda, a importância da Gincana de Caxiuanã para as populações da FLONA, que é uma das atividades do Programa Floresta Modelo de Caxiuanã, desenvolvido na Estação desde 1997. Este evento vem gerando rico acervo didático, que será divulgado, brevemente, em publicação específica.

Oartigo, de autoria de Antonio Carlos Lobo Soares e Pedro Lisboa, esclarece dados interessantes sobre a subsistência da Estação, como a média de investimentos em manutenção, que, segundo os autores, não ultrapassou, nos últimos sete anos, 1\% do orçamento do Museu Goeldi. À luz da intensa atividade científica ali presente e dos resultados alcançados por meio da produção científica gerada, mais de 680 trabalhos científicos publicados em 15 anos, pode-se afirmar que o investimento feito em Caxiuanã pelo Ministério da Ciência e Tecnologia teve um retorno notável em termos de produção cientíica, acessível pela sociedade brasileira na forma de conhecimento que impulsionará o desenvolvimento sustentável da Amazônia e que também permite a análise de mudanças globais, uma vez que Caxiuanã abriga programas que têm por finalidade a comparação de indicadores de sustentabilidade em vários locais do planeta. Em 15 anos de funcionamento foram produzidas 15 teses de doutorado, o que equivale a uma tese por ano, 60 dissertações de mestrado, o que equivale a quatro dissertações por ano, 61 trabalhos de conclusão de curso de graduação ou monografias, e 544 artigos em periódicos nacionais e internacionais, formando um mosaico de conhecimento sobre os 330 mil hectares da FLONA, mostrando que a Estação tem capacidade intrínseca para funcionar como laboratório vivo no estudo das ciências sociais e naturais na Amazônia.

A segunda parte, "Clima", com quatro capítulos, trata da climatologia da região de Caxiuanã. É encabeçada por resultados do experimento ESECAFLOR ("Estudo da Seca na Floresta"), vinculado ao Experimento em Grande Escala da Biosfera-Atmosfera da Amazônia (LBA), onde uma parcela da floresta está sob o impacto da indução de um período de seca para avaliar os fluxos de água e dióxido de carbono. Várias pesquisas visam

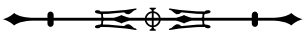


entender o comportamento das raízes submetidas a diferentes condições de umidade; a precipitação pluvial sobre Caxiuanã, a infiltração de água e o fluxo de CO2, além da transpiração vegetal; o incremento da biomassa aérea, medições de liteira e conteúdo de água no solo. Os leitores terão respostas a todos estes temas. Outras contribuições relatam o comportamento da precipitação pluviométrica na região noroeste de Caxiuanã, onde nos últimos anos as alterações da cobertura vegetal natural foram intensas. Incluem-se, ainda, estudos da radiação solar, dos fluxos de energia radioativa e da concentração de gases atmosféricos. Como se vive a era em que as mudanças climáticas ocupam a preocupação de grande parte dos cientistas e dos ambientalistas, a contribuição para o avanço do conhecimento nesta área é inegável.

Na terceira parte, sobre "Solos", com sete capítulos, são oferecidas informações sobre a caracterização, distribuição espacial, variabilidade sazonal de solos em floresta de terra firme, inclusive dos solos da grade amostral do Programa de Pesquisa em Biodiversidade (PPBio). Os solos dos sítios de terra preta foram mais intensamente estudados. Nestes, foram abordados temas sobre as suas classes texturais e as principais características químicas, bem como sobre a população e diversidade microbiana; a sua relação com a mandioca (Manihot esculenta Crantz) e o potencial tecnológico quando cultivada em solo de terra preta arqueológica pela agricultura familiar.

As pesquisas botânicas aparecem na quarta parte, com oito capítulos. Estão focadas em estudos mais gerais sobre a flora arbórea, bem como em grupos botânicos específicos, que variam desde a flora mono e dicotiledônea até aos chamados criptógamos (vegetais que não produzem flor), permeando também estudos polínicos, citogenéticos, morfológicos e quimiotaxonômicos. Os estudos gerais abrangem levantamentos florísticos que comparam dados de área basal, volume e fitomassa de áreas exploradas e primárias, deduzindo que a exploração madeireira convencional (sem utilização das técnicas de manejo florestal), além de causar impacto ecológico ao ambiente, é insustentável do ponto de vista econômico. Outros estudos avaliaram a composição e a diversidade arbórea de floresta primária de terra firme, comparando com a diversidade e a composição florística do seu banco de sementes, bem como os efeitos da exclusão hídrica no banco. Entre os estudos mais específicos da flora, destacase o estudo taxonômico das Euphorbiaceae da Floresta Nacional de Caxiuanã, as quais estão distribuídas em cinco subfamílias, nove tribos, cinco subtribos e doze gêneros. Quanto aos criptógamos, o estudo da riqueza específica e da abundância de musgos e hepáticas indica que a ECFP é uma área preservada com alta diversidade briológica. Na pesquisa palinológica foi feito o estudo morfopolínico de macrófitas aquáticas visando sua identificação em sedimentos de lagos, igarapés, rios e baías. Em relação à citogenética, foi enfocada a diversidade genética e morfológica de indivíduos de Anthurium Schott (Araceae), utilizando as espécies Anthurium sp. nov., A. eminens, $A$. harleyi e $A$. gracile. No estudo quimiotaxonômico, que foi somado ao estudo de sazonalidade e de atividade biológica, a espécie trabalhada foi Piper divaricatum. Os autores observaram, mais uma vez, que as espécies de Piper que crescem na Amazônia produzem óleos essenciais ricos em monoterpenos e sesquiterpenos.

Os estudos de fungos de Caxiuanã cresceram bastante nos anos mais recentes, merecendo no livro o destaque para compor a quinta parte, "Fungos", que reúne três estudos sobre Uredinales, Agaricomycetes e Hifomicetos associados a palmeiras.

Os estudos de fauna, reunidos na parte seis, "Fauna", com 17 capítulos, trazem informações sobre diversos grupos animais que habitam a floresta de Caxiuanã, sendo que muitos deles vêm sendo objetos de pesquisas sistemáticas de diversidade, como colêmbolos, Lutzomyia (Phlebotominae), moscas Calliphoridae e Sarcophagidae (Diptera), gafanhotos das famílias Acrididae, Paulinidae, Pyrgomorphidae e Romaleidae.

Em relação às formigas-de-correição, conhecidas como 'taocas', foram identificadas 11 espécies, das quais as 
duas espécies de Neivamyrmex representam novos registros para o estado do Pará. Ainda com relação às formigas, estudos registraram 36 espécies pertencentes aos gêneros Crematogaster, Gnamptogenys e Pachycondyla e 27 de Attini, estas representadas por nove gêneros, além de estudo de espécies do gênero Odontomachus. Porém, um dos artigos que impressionam pela sua extensão, clareza e ilustração é o que aborda as aranhas de Caxiuanã, pois revela o enorme esforço no conhecimento destes insetos, sumarizando os dados faunísticos disponíveis sobre oito ordens de aracnídeos presentes na região. Os esforços empreendidos nos últimos dez anos permitem inferir que a FLONA pode ser considerada como uma das áreas mais bem conhecidas da Amazônia brasileira em relação à fauna de aracnídeos.

Nas relações inseto-planta, destacam-se as contribuições que abordam a polinização de Theobroma speciosum por moscas Drosophilidae e de insetos associados a Montrichardia linifera (Araceae), no rio Curuá, como lagartas de Helicopis cupido (Lepidoptera: Riodinidae) e ninfas e adultos de Tetrataenia surinama. Um trabalho referente a gafanhotos capturados em Caxiuanã identificou quatro famílias, o que possibilitou a elaboração de uma lista de 52 espécies de Acridoidea.

O estudo dos répteis, que vem desde os primórdios das pesquisas em Caxiuanã, está representado no livro com um artigo sobre o comportamento de duas espécies de lagartos Anolis e outro sobre a diversidade de serpentes da região. Com os dados já disponíveis, somados aos reunidos nesta pesquisa, já se sabe que a região de Caxiuanã apresenta 70 espécies de serpente. Os estudos de peixes, que também vêm sendo objeto de pesquisas há alguns anos, mostram que até o ano de 2004 foram registradas 208 espécies distribuídas em três ambientes principais: associados aos pequenos igarapés, à vegetação flutuante e às áreas abertas dos igarapés, rios e baías de Caxiuanã. Esses estudos revelam também que a pesca na região da FLONA apresenta-se, de maneira geral, incipiente, uma vez que é exclusivamente de subsistência. Entre os mamíferos, o único grupo a merecer um artigo é o de morcegos, que oferece uma caracterização da composição, riqueza e diversidade de quirópteros de Caxiuanã.

Parte do desejo expresso no primeiro volume publicado sobre as pesquisas realizadas em Caxiuanã, em 1999, é hoje uma realidade. A Estação Científica Ferreira Penna, ao ser instalada em Caxiuanã, tornou-se referência em pesquisa científica na Amazônia. $\bigcirc$ desafio, a partir de agora, é transformar o conhecimento ali gerado em subsídios para a elaboração de políticas públicas que promovam a conservação dos recursos naturais e a inclusão social dos moradores desta e de outras florestas nacionais no Brasil, justificando definitivamente este esforço do Museu Paraense Emílio Goeldi. É gratificante ver os resultados das pesquisas mais recentes realizadas em Caxiuanã reunidos em um volume bem elaborado e ilustrado, mantendo o alto padrão estabelecido pelo Museu Goeldi para suas publicações. 
